\title{
Reflexões e Desenvolvimento de Conhecimentos para o Ensino de Medidas de Tendência Central Gerados por Professores Participantes de um Processo Formativo
}

\section{Reflections and Developing Knowledge for Teaching Measures of Central Tendency by Teachers in Training}

\author{
Tiago Augusto Alves ; Angelica da Fontoura Garcia Silva ${ }^{\mathrm{ab}}$; Marta Élid Amorimª
}

\begin{abstract}
aUniversidade Anhanguera de São Paulo, Programa de Pós-Graduação Stricto Sensu em Educação Matemática. SP, Brasil. bUnopar, Programa de Pós-Graduação Stricto Sensu Metodologias para o Ensino de Linguagens e suas Tecnologias, PR, Brasil *E-mail: angelicafontoura@anhanguera.com
\end{abstract}

\begin{abstract}
Resumo
Este artigo descreve parte de uma investigação realizada num contexto de formação continuada, da qual participaram professores que lecionam Matemática para os anos finais do Ensino Fundamental e Médio. Buscou-se compreender quais são os conhecimentos explicitados e as reflexões geradas durante uma sessão de formação na qual se propôs discutir e refletir sobre os significados das Medidas de Tendência Central - MTC - a partir da análise de situações contextualizadas. O estudo foi desenvolvido no âmbito do Projeto Observatório da Educação. Para desenvolvê-lo, optou-se pela metodologia qualitativa por meio da qual procurou-se descrever e interpretar a participação de 12 professores a partir dos dados coletados em uma das sessões de formação e das respostas dadas por eles a um questionário inicial de pesquisa. Os dados analisados referemse à produção escrita dos participantes e a transcrição dos vídeos da formação e se deu à luz de teorias a respeito da base de conhecimentos necessários ao ensino - Ball, Thames \& Phelps - e reflexão sobre a prática - Zeichner. A análise das reflexões geradas a partir das situações apresentadas possibilitou ao grupo refletir em aspectos importantes das MTC, sobretudo da moda. Foi possível notar a ampliação da base de conhecimentos profissionais dos participantes, especialmente o Conhecimento do Conteúdo e do Ensino. Além disso, há indícios da ampliação do nível de Letramento Estatístico dos participantes desta investigação.
\end{abstract}

Palavras-chave: Formação Continuada de Professores. Conhecimento Profissional Docente. Reflexão sobre a Prática. Ensino de MTC.

\begin{abstract}
This article describes part of an investigation carried out in a continuing education context, with the participation of Mathematics teachers for the final years of Primary and Secondary Education. Our goal was to understand their explicit knowledge and reflections during a training session in which we proposed discussing and reflecting on the meanings of Measures and Central Tendency - MCT, based on the analysis of contextualized situations. The study was developed in the scope of the Education Observatory Project. In developing it, we chose a qualitative methodology through which we aimed to describe and interpret the participation of 12 teachers based on data collected in one of the training sessions and the answers they provided on an initial research questionnaire. The analyzed data refer to the written production of the participants and the transcription of the training videos and was carried out according to theories on the knowledge base needed for teaching - Ball, Thames and Phelps - and reflections on the teaching practice - Zeichner. Analyzing the reflections in the situations presented enabled the group to reflect on important aspects of MCT, particularly mode. We observed an increase in the professional knowledge base of the participants, especially their Content Knowledge and Teaching Knowledge. Moreover, there are indications of a heightened level of Statistical Literacy of the participants in this investigation.
\end{abstract}

Keywords: Continuing Education for Teachers. Teacher Knowledge. Reflections on the Teaching Practice. Teaching MCT.

\section{Introdução}

Este artigo apresenta resultados da investigação de Alves (2016) que integra um conjunto de pesquisas sobre conhecimentos de professores da Educação Básica para ensinar Probabilidade e Estatística desenvolvidas no Programa de Pós-Graduação em Educação Matemática da Universidade Anhanguera de São Paulo pelo Grupo de Formação de Professores e financiadas pela Coordenação de Aperfeiçoamento de Pessoal de Nível Superior (CAPES).

Estudos desse grupo foram desenvolvidos e aproximaram a universidade das escolas públicas, uma vez que tinham por finalidade investigar a ampliação da base de conhecimentos de grupo de professores de Matemática da Educação Básica para ensinar noções de Estatística, mediante a proposição de cursos de formação continuada (Sera, 2016; Macedo, 2016).
Os pressupostos dessas pesquisas, assim como os utilizados por este estudo, ancoravam-se em promover reflexões compartilhadas sobre o Letramento Estatístico e envolviam questões relacionadas às dificuldades de ensinar noções sobre o tema.

Apoiados em Gal (2004), assumimos que o Letramento Estatístico está intrinsecamente ligado à competência que o cidadão deve desenvolver para avaliar e interpretar com criticidade informações estatísticas. Para esse autor, o cidadão será considerado estatisticamente letrado se possuir uma base de conhecimentos que lhe permita organizar e comunicar informações coletadas em diferentes contextos, além de argumentar sobre os motivos que o levaram a chegar às suas conclusões.

Tal fato, também, é discutido por Batanero \& Godino 
(2005). Esses autores destacam que os próprios estatísticos defendem a Educação Estatística para todos os indivíduos, algo que tem ganhado força entre os educadores matemáticos. Os pesquisadores defendem uma inserção cada vez maior da Estatística nos currículos de Matemática, desde os anos iniciais do Ensino Fundamental.

No Brasil, a Base Nacional Comum Curricular (BNCC) dá indicações estritas para a inclusão de conteúdos estatísticos nos currículos da Educação Básica. Os temas relacionados ao ensino da estatística estão organizados em uma unidade temática obrigatória, denominada "Probabilidade e Estatística". Como nos mostra o trecho a seguir, é esperado que os alunos, ao final do Ensino Fundamental,

(...) saibam planejar e construir relatórios de pesquisas estatísticas descritivas, incluindo medidas de tendência central e construção de tabelas e diversos tipos de gráfico. Esse planejamento inclui a definição de questões relevantes e da população a ser pesquisada, a decisão sobre a necessidade ou não de usar amostra e, quando for o caso, a seleção de seus elementos por meio de uma adequada técnica de amostragem. (Brasil, 2018, p. 275)

Para tanto, os professores precisam estar preparados para planejar a instrução de maneira a levar os alunos a desenvolverem essas habilidades. No entanto, Arteaga et al. (2012) consideram que os professores não têm a formação adequada para ensinar nem conceitos estatísticos e de probabilidade. Esse fato também foi constatado na realidade brasileira por Kataoka et al. (2008), que concluíram que os professores normalmente têm formação em Probabilidade e Estatística nos cursos de formação inicial, mas não desenvolveram conhecimentos específicos para o seu ensino.

Podemos justificar, assim, a relevância da escolha do tema Ensino de Estatística para nossa investigação. Considerase, ainda, que os docentes, participantes desta pesquisa e do processo formativo, tinham como tarefa a implementação de um currículo fundamentado na BNCC (Brasil, 2018) e que a proposta pode contribuir para um apoio efetivo ao trabalho do professor em sala de aula com vistas à promoção do letramento estatístico e ao alcance dos objetivos previstos nas orientações curriculares.

\section{Marco Teórico: Conhecimento Profissional e Reflexão Sobre a Prática}

Sob nosso ponto de vista, o professor tem papel fundamental nos processos de ensino e aprendizagem, pois ele é um elemento-chave quando pensamos na necessidade de promover a aprendizagem da Matemática com compreensão. Por isso, consideramos que é imprescindível refletir sobre a base de conhecimentos necessários ao ensino em um contexto formativo.

Para elaborar os "casos de ensino" utilizados durante o processo formativo, inspiramo-nos na definição de "caso" proposta por Shulman $(1986,1996)$; e para proceder à análise dos dados coletados neste estudo, nós nos apoiamos nas categorias distintas de conhecimentos descritas por Ball et al. (2008) e nas pesquisas sobre reflexão coletiva na prática como proposto por Zeichner (2008).

No final da década de 80, Shulman (1986) ampliou as discussões acadêmicas a respeito do conhecimento profissional docente, além disso, esse mesmo autor trouxe a ideia de casos. Para Shulman (1996, p. 208), a aprendizagem não ocorre somente a partir da nossa experiência, também "aprendemos pensando sobre nossa experiência", e "um caso é uma versão relembrada, recontada, reexperienciada e refletida de uma experiência direta. $\mathrm{O}$ processo de relembrar, recontar, reviver e refletir é o processo de aprender pela experiência" (Shulman, 1996, p.208, tradução nossa). Observa-se, aqui, uma ideia de elaborar os "casos" a partir da própria experiência profissional do professor. Tal ideia era defendida desde 1986 pelo autor. $\mathrm{Na}$ época, ele defendia a utilização do que ele chamava de "literatura de casos" em processos formativos e discutia que tal proposta poderia relacionar a teoria e a prática:

(...) não estou argumentando que a preparação de professores seja reduzida para o mais prático e concreto; em vez disso, estou usando o poder de uma literatura de caso para iluminar tanto o prático quanto o teórico; argumento para o desenvolvimento de uma literatura de caso, cuja organização e utilização será profunda e conscientemente teórica. (Shulman, 1986, p. 11, tradução nossa)

Em 1996, esse pesquisador denominava tal estratégia como método de casos e discutia uma possibilidade de organizar as experiências profissionais dos docentes envolvidos em processos formativos.

(...) Métodos de casos, assim, se tornam estratégias para ajudar professores a 'agrupar' suas experiências em unidades que podem se tornar foco para prática reflexiva. Podem se tornar base para a aprendizagem individual do professor, assim como uma forma com a qual comunidades de professores, tanto local como mais ampliada, [...] podem armazenar, trocar e organizar suas experiências (Shulman, 1996, p. 199))

Concordamos com o autor quanto ao uso dos casos para refletir sobre as experiências vivenciadas pelos professores, todavia, nesta investigação, não nos apoiaremos nas experiências dos professores para apresentar a problemática a ser estudada pelo grupo. Em nossa investigação denominaremos Casos de Ensino como um caso que descreve uma situação real ou fictícia que ocorreu em um contexto de sala de aula e que pode servir para apresentar a problemática a ser discutida pelo grupo. Da mesma forma que Shulman (1986), consideramos que os Casos de Ensino podem nos ajudar a ilustrar ou exemplificar situações ou proposições teóricas e aproximar os participantes da prática, mesmo que, no momento, não seja a prática deles, ela os aproxima de práticas diversas.

Também foi por meio da análise das diferentes categorias de conhecimentos profissionais propostas por Shulman (1986) - conhecimento do conteúdo específico, conhecimento pedagógico do conteúdo e conhecimento curricular do conteúdo - que Ball et al. (2008) apresentaram um refinamento 
dessa categorização, aplicada ao professor de Matemática, e a denominaram base de conhecimentos necessários para o ensino da Matemática.

Ball et al. (2008) refinaram as três categorias propostas por Shulman (1986) em: conhecimento comum do conteúdo, conhecimento do horizonte do conteúdo; conhecimento especializado do conteúdo; conhecimento do conteúdo e dos estudantes; conhecimento do conteúdo e do ensino e, finalmente, conhecimento curricular do conteúdo, os quais serão descritos a seguir.

O conhecimento comum do conteúdo segundo Ball et al. (2008), abrange o conhecimento do assunto e o de suas estruturas organizacionais necessárias para ensinar. Esse conhecimento permite ao professor utilizar corretamente, por exemplo, termos, representações e notações durante suas aulas, assim como identificar incorreções ou inadequações, quer em produções dos alunos, quer em materiais didáticos. O conhecimento do horizonte do conteúdo se refere a como os conteúdos matemáticos se relacionam, ou seja, identificar quais noções já fazem ou deveriam fazer parte do repertório do aluno, as quais precisariam ser mobilizadas durante o ensino de uma nova ideia. O conhecimento especializado do conteúdo diz respeito ao conhecimento matemático unicamente utilizado para o ensino, ou seja, apesar de ser específico do ensino, não faz parte obrigatória dos conteúdos a serem ensinados aos alunos. Para os autores, esse conhecimento está relacionado à capacidade de compreender quais seriam as possíveis causas de erros dos alunos e apresentar a eles explicações precisas e respostas viáveis do ponto de vista da Matemática.

O conhecimento do conteúdo e dos estudantes associa a compreensão da Matemática ao conhecimento do pensamento matemático desses alunos, permitindo ao professor previsão e interpretação de erros mais comuns do grupo e a busca de estratégias de superação. Nesse caso, a experiência docente auxilia no diagnóstico dos erros e de suas possíveis causas. O conhecimento do conteúdo e do ensino é, para Ball et al. (2008), a combinação do domínio dos conteúdos específicos da disciplina Matemática com a compreensão de assuntos pedagógicos que, de alguma forma, estão presentes no processo de ensino e aprendizagem. Finalmente, o conhecimento curricular do conteúdo refere-se ao conhecimento dos professores dos temas e dos tópicos dos programas de ensino, diretrizes e recomendações curriculares.

Além das categorias estabelecidas por Ball et al. (2008), no processo de formação continuada, cenário desta pesquisa, procuramos analisar como se deu a reflexão coletiva com base nos estudos de Zeichner (1993). O autor afirma que os professores constroem teorias a partir de suas práticas e que é importante que tais teorias sejam observadas e discutidas de forma coletiva. Para Zeichner (1993), a prática docente é "[...] o resultado de uma ou de outra teoria, quer ela seja reconhecida ou não. Os professores estão sempre a teorizar, à medida que são confrontados com vários problemas pedagógicos, tais como a diferença entre suas expectativas e os resultados" (Zeichner, 1993, p.21). Sob a perspectiva de Zeichner, a reflexão é uma atividade coletiva, embora seja também, por vezes, individual. Nessa perspectiva, a reflexão acontece quando o professor leva em consideração o que outras pessoas pensaram e não, necessariamente, ele mesmo. Assim, neste estudo optamos por trazer extratos dos diálogos ocorridos na sessão de formação aqui analisada, em que estão evidenciadas as discussões e as reflexões coletivas dos participantes a respeito das ideias ligadas às Medidas de Tendência Central (MTC) discutidas durante a formação.

\section{Contexto e Método}

Para o desenvolvimento desta investigação tínhamos como objetivo compreender quais são os conhecimentos explicitados e as reflexões geradas durante uma sessão de formação continuada. Ao longo da formação foi proposto discutir e refletir sobre os significados das Medidas de Tendência Central a partir da análise de situações contextualizadas. Para tanto, seguimos abordagem qualitativa, segundo as características descritas por Bogdan e Biklen (1994). Desenvolveu-se no âmbito do Projeto Observatório da Educação $^{1}$, projeto de formação e pesquisa constituído por professores e pesquisadores da área da Educação Matemática, ligado ao Programa de Pós-Graduação em Educação Matemática da Universidade Anhanguera de São Paulo - Brasil, e financiado pela Coordenação de Aperfeiçoamento de Pessoal de Nível Superior - CAPES. O referido projeto buscou a constituição de grupos colaborativos ${ }^{2}$ de formação e pesquisa a fim de investigar a prática docente e contribuir para transformá-la e promover o desenvolvimento profissional de professores que lecionam Matemática, quando inseridos em um processo de pesquisa em Educação Matemática e motivados a promover inovações curriculares nas suas aulas.

$\mathrm{O}$ estudo foi realizado durante um processo formativo e contou com a participação de 14 professores que lecionavam no Ensino Fundamental e Médio da Educação Básica em escolas públicas de São Paulo e quatro pesquisadores que planejaram e conduziram o processo. Todavia, na sessão de formação que analisamos neste artigo compareceram 12 participantes, que foram referenciados pelas letras A, B, C, ... e L e os quatro pesquisadores, 1, 2, 3 e 4, a fim de garantir o anonimato de suas identidades. Todos eram licenciados em Matemática, com uma média de idade de quarenta e cinco anos, com desvio-padrão igual a nove, aproximadamente. O tempo de atuação profissional apresentou uma média de

1 Projeto Observatório da Educação, Auxílio no 1052/2013 D.O. 30/07/2013: Investigações sobre o Processo de Ensino e de Aprendizagem de Conceitos concernentes à Probabilidade e Estatística, foi avaliado pelo Comitê de Ética - CEP/CONEP - e obteve a aprovação sob o número 982.198 . Coordenado pelo Professor Doutor Ruy César Pietropaolo.

2 Em termos de organização social, alguns autores têm apresentado e discutido a respeito de grupos colaborativos como um empreendimento social constituído a partir de um trabalho voluntário em que seus membros delineiam um objetivo comum (Santana \& Barbosa, 2015). 
quinze anos, com desvio-padrão de valor igual a sete. Não havia uma correlação entre a idade dos docentes e o tempo deles de atuação no ensino, assim o grupo investigado era bem diversificado. Além disso, nove desses profissionais informaram que já lecionaram o conteúdo investigado em algum momento.

Para coletar os dados aqui analisados, reunimos o grupo de professores em uma sessão de formação para que discutissem questões e Casos de Ensino que serão expostos na seção de resultados e análise dos dados, por meio dos quais identificaríamos os conhecimentos dos professores acerca de MTC. Vale destacar, que os dados foram coletados por meio da recolha dos registros escritos e das gravações em vídeo ocorridas durante as discussões do grupo.

Conforme já referido, a seguir apresentamos a análise dos dados sob a perspectiva de Ball et al. (2008) e Zeichner (2008), com vistas ao desenvolvimento da base de conhecimentos necessários ao ensino de MTC e à reflexão coletiva. Tais referências nos serviram de categorias de análise préestabelecidas.

\section{Discussão e Análise dos Dados}

No início do processo formativo, propusemos a análise de um caso, cujo foco encontrava-se na reflexão e discussão dos significados, características e importância das MTC, sobretudo da moda, na análise e representação de um conjunto de dados. Para tanto, utilizamos o número do calçado de cada um dos professores a fim de que tivéssemos os elementos para compor a investigação. Consideramos que utilizar dados fornecidos pelos próprios participantes favoreceria a inserção desses docentes no contexto a ser analisado, aproximando-os de uma situação prática.

Assim sendo, para dar início à atividade, foi solicitado aos 12 professores presentes e aos quatro mediadores desta investigação que informassem quais os números dos calçados que estavam utilizando e, simultaneamente e à vista de todos, os valores foram registrados na lousa (Figura 1).

Figura 1 - Registros dos números de calçados coletados

$$
43,44,43,39,44,37,36,33,41,43,39,36,44,36,40,45
$$

Fonte: Dados da pesquisa.

Diante dos valores apresentados, o Pesquisador 1 colocou a seguinte situação-problema (Figura 2):

Figura 2 - Situação-problema apresentada aos professores Considerem que esses valores são uma amostra de dados dos calçados de uma população, utilizada por uma fábrica para analisar quanto que ela deve produzir de cada numeração. Qual seria o valor que representa a maior necessidade de produção para essa fábrica? (Pesquisador 1) Fonte: Dados da pesquisa.

A partir disso, alguns professores se pronunciaram, como o Professor B, que sugeriu que fosse calculada a moda dos valores. Entretanto, os Professores I e F acrescentaram que, antes disso, seria melhor que os dados fossem separados em dois grupos: calçados masculinos e calçados femininos.

Frente às sugestões apresentadas e a fim de motivar uma discussão sobre as características das MTC para esse tipo de situação-problema, o Pesquisador 2 sugeriu que os professores calculassem a média, a mediana e a moda de todos os dados de cada grupo, obtendo-se os valores apresentados na Figura 3.

Figura 3 - Registros das MTC dos números de calçados coletados

\begin{tabular}{|c|c|c|c|}
\cline { 2 - 4 } \multicolumn{1}{c|}{} & $\begin{array}{c}\text { Todos os } \\
\text { dados }\end{array}$ & $\begin{array}{c}\text { Grupo } \\
\text { Masculino }\end{array}$ & $\begin{array}{c}\text { Grupo } \\
\text { Feminino }\end{array}$ \\
\hline Média & 40,19 & 42,6 & 36,17 \\
\hline Mediana & 40,5 & 43 & 36 \\
\hline Moda & 36,43 e 44 & 43 e 44 & 36 \\
\hline
\end{tabular}

Fonte: Dados da pesquisa.

Dando prosseguimento à atividade, o Pesquisador 1 questionou os professores acerca de qual dos valores poderia responder ao problema proposto.

Assim, o Professor $\mathrm{H}$ apresentou os números 43 e 44 como os de necessidade de maior fabricação para os homens. Da mesma maneira, o Professor J acrescentou que, para as mulheres, seria o número 36.

A escolha da moda como primeira opção de alguns professores sugere que eles reconhecem os conceitos básicos dessa medida como o valor de maior frequência entre os dados analisados, o que pode ser relacionado ao Conhecimento Comum do Conteúdo de Ball et al. (2008). É provável que isso tenha ocorrido até pelo modo como fora apresentada a situação-problema, uma vez que foi solicitado que determinassem o valor que representaria a maior necessidade de produção da fábrica de calçados. É importante destacar que o Professor $\mathrm{H}$ apontou dois valores para a moda, o que demonstra que ele reconheceu que o conjunto composto pelos números de calçados masculinos era bimodal.

O Pesquisador 2, a fim de acrescentar maiores informações estatísticas - como representatividade de amostra - e conduzir os professores a refletirem acerca do assunto, fez as seguintes considerações:

Outro ponto que pode ser discutido é se nós somos representativos para a população. Ou seja, associar o grau de probabilidade de confiabilidade da nossa amostra, o intervalo de confiança e a margem de erro, para saber se somos representativos ou não. Quando ocorre uma liquidação de sapatos, o número que mais pessoas calçam é aquele que acaba primeiro. Eu observo que, geralmente, acabam primeiro para os homens os números 41 e 42 . Em contrapartida, acredito que a amostra das mulheres aqui possa representar a população (Pesquisador 2).

Dando prosseguimento à atividade, o Pesquisador 1 perguntou aos participantes se todos concordavam que os números 36, 43 e 44 seriam os valores que melhor representariam os dados e eles disseram que sim.

Para instigar a discussão entre os participantes, o Pesquisador 2 perguntou se eles percebiam que, para aquela situação, não teria muito significado o cálculo da média. Disso, surgiram as discussões relatadas no episódio a seguir (Figura 4): 
Figura 4 - Episódio 1

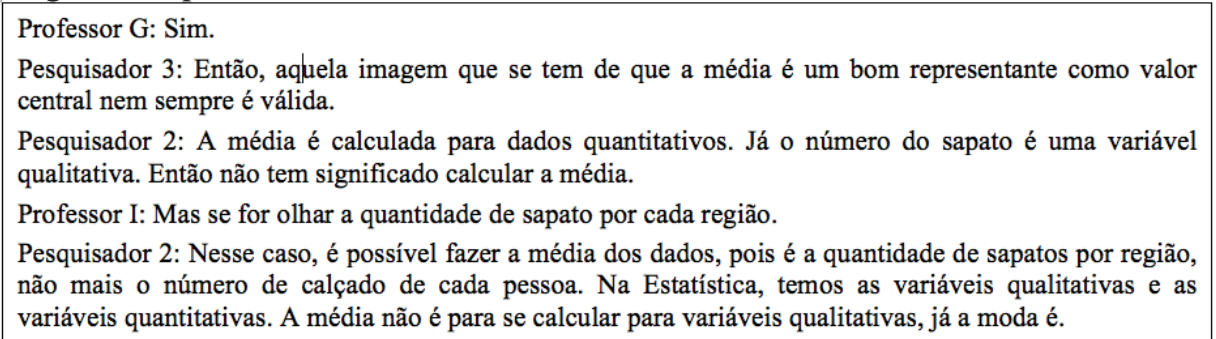

Fonte: Dados da pesquisa.

Diante disso, o Professor B concluiu: "Como vai medir o meu pé [de todos os participantes] e tirar uma média? Realmente, isso não tem sentido". O referido docente aproveitou o momento para levantar outra reflexão: "Também acho que a mediana não teria sentido, não é?".

Por conseguinte, o Pesquisador 2 esclareceu que, naquele caso, seria apenas para saber, por exemplo, que metade das pessoas calçava igual ou menor que certo número, ou seja, a mediana não teria muito significado para o objetivo da questão. Nesse mesmo momento, alguns professores demonstraram que, até aquela discussão, eles não utilizavam exemplos contextualizados para os alunos. (Figura 5)

Figura 5 - Episódio 2

Professor A: Nossa, eu nunca dei muito valor para a moda, eu só explicava o que era e pedia para que
os alunos me dissessem a moda depois de eu dar um conjunto de dados, sem contexto algum.
Professor D: Eu também não utilizava problemas práticos assim, agora esta situação me chamou a
atenção, porque é assim mesmo, neste tipo de comércio quem está administrando precisa levar isso em
conta.
Professor A: Engraçado que eu vivo falando de contexto e focava mais a média e não contextualizava a
moda, esse exemplo é ótimo para a gente aplicar na sala, os alunos vão gostar de discutir isso.

Fonte: Dados da pesquisa.

Dando continuidade às discussões sobre o tipo de variável, o professor $\mathrm{G}$ comentou que as cores mais comuns de carros eram a preta e a prata. Então o Pesquisador 2 questionou os participantes: "E como vai tirar a média das cores?".

Com isso, os professores concordaram que não seria possível fazer a média entre as cores, assim como entre os números de calçados. Muito provavelmente, eles perceberam que, quando os dados são de natureza qualitativa, a moda é a mais adequada dentre as MTC para representá-los, demonstrando uma familiarização dos participantes com conceitos básicos relacionados com a estatística descritiva, aspecto do Letramento Estatístico de Gal (2004) relacionado ao elemento Conhecimentos Estatísticos. Além disso, a partir da análise dos dois episódios aqui elencados, acrescidos das observações dos professores, como, aquelas apresentadas pelo Professor G, já é possível observar indícios de ampliação do conhecimento do conteúdo e do ensino como descrito por Ball et al. (2008). Notamos que a discussão desse conteúdo específico da disciplina - Moda - levou os participantes a refletirem sobre questões pedagógicas relacionadas ao ensino da temática.

A fim de sistematizar os conhecimentos desenvolvidos no encontro e possibilitar que fossem ampliados, o Pesquisador 1 trouxe à discussão a propriedade da média acerca da natureza de seu valor frente às variáveis analisadas. Para tanto, recorreu à Questão $n^{0} 7$ do Questionário Inicial (Figura 6) que foi respondido pelo grupo antes do início do processo formativo, cujo contexto se refere a uma aluna chamada Carolina, a qual julgou duvidosa certa informação que era relacionada a um valor decimal para a média em um contexto no qual as variáveis eram números inteiros. Nela buscamos observar, dentre outros e com base na categorização de Ball et al. (2008), os domínios do Conhecimento do Conteúdo e do Ensino e do Conhecimento do Conteúdo e do Estudante, uma vez que caberia ao professor reconhecer o conflito cognitivo enfrentado pela aluna e propor um meio para levá-la à compreensão.

Figura 6 - Questão $n^{\circ} 7$ do Questionário Inicial

Carolina viu a seguinte informação enquanto navegava na internet: "Em 1970, a mulher brasileira tinha,
em média, 5,8 filhos. Trinta anos depois, esta média era de 2,3 filhos." Ela julgou duvidosa essa
informação, pois os valores dessas médias não são números inteiros.
Você concorda com a avaliação de Carolina? Caso discorde, que explicação você utilizaria para
convencê-la de sua opinião?

Fonte: Dados da pesquisa.

A análise das respostas dadas antes do início da formação permitiu observar que a maioria dos participantes não concordou com a avaliação de Carolina, personagem de nossa situação-problema, mas nem todos justificaram suas respostas. 
A partir disso e para favorecer a reflexão entre os participantes, os Pesquisadores 1 e 2, mediadores da discussão, fizeram as seguintes observações:

Pesquisador 1: Aqui tem o detalhe que a quantidade de 2,3 filhos chamou a atenção de Carolina. Isso tem a ver com uma das propriedades da média, na qual, considerando um conjunto de dados, é possível obter uma média de grandeza diferente da grandeza dos dados do conjunto. Ou seja, são dados inteiros que possuem como média um valor na representação decimal.

Pesquisador 2: Alguns alunos têm dificuldade em aceitar isso. E esses números são utilizados para comparar. Por exemplo, em um campeonato de futebol, um time teve uma média de 2,7 gols e o outro teve 2,3. Ou seja, por partida, em média, os dois fizeram mais de dois gols, mas um está mais próximo de 3 gols e o outro de 2. Então a média pode ser de natureza diferente dos números analisados e isso é uma dificuldade entre os alunos.

O obstáculo cognitivo apontado pelo Pesquisador 2 está relacionado a resultados de pesquisas, como os de Strauss e Bichler (1988), cujos estudos demonstraram que uma das dificuldades enfrentadas pelos alunos investigados era reconhecer que a média pode ser um número de natureza diferente daquela observada entre os valores analisados.
Diante disso, o Professor G comentou que cabe ao professor saber esses diferentes aspectos da média, de modo que possa lecionar o conteúdo corretamente. Para isso, fez uma retomada da atividade prática anterior. Ele concordava que seria necessário realizar o arredondamento da média calculada para obter um número para representar o conjunto de estimativas do grupo. A partir de sua reflexão, o professor demonstrou que são dois aspectos da média que devem ser considerados na prática didática: "Nós professores temos que saber explicar que uma coisa é a média, que pode ser, por exemplo, trezentos e tantos inteiros e dois décimos. Outra coisa é você ter arredondado para dar uma estimativa".

O Professor $\mathrm{G}$ complementou, ainda, que trabalhar tal conteúdo com os alunos poderia ser uma dificuldade: “(...) porque aqui [média de natureza diferente dos dados], acho que todo mundo fica pensando a mesma coisa: como vou fazer com os alunos?".

A fim de conduzir o professor a solucionar o conflito que havia percebido, o Pesquisador 2 ressaltou que o aspecto da média a ser considerado depende do objetivo da questãoproblema que estiver sendo analisada. A partir disso, surgiram as reflexões apresentadas na Figura 7:

Figura 7 - Episódio 3

Pesquisador 2: Naquele contexto nós tínhamos que arredondar [referindo-se a uma atividade proposta no
encontro anterior, na qual solicitamos que os participantes estimassem a quantidade de confeitos que
havia em uma vasilha transparente]. Pois não teria sentido, por exemplo, dizer que o grupo achava que no
pote tinha 318,7 balas. Mas, na questão que tratava da média dos filhos, eu não poderia arredondar, pois
ali o objetivo é comparar quantidade de filhos e a escala é pequena. Mas se fosse uma situação em que o
valor fosse muito grande, a escala seria muito grande, você poderia aproximar, mesmo o valor tendo
decimais.
Professor H: Poderia também, para representar essa situação, dizer que, a cada dez mães, tem tantos
filhos. Seria uma forma diferente de explicar a mesma coisa.
Pesquisador 3: Isso seria outra maneira de explicar o significado do valor da média, mas é importante
perceber que ali na questão a função das médias é comparação de valores, de índices.
Professor G: Eu estava pensando. Quais seriam os exemplos que a gente poderia trabalhar em sala de aula
que levasse o aluno a enxergar de uma maneira diferente? Isso eu acho difícil. Acho difícil você encontrar
a coisa certa para conduzir o aluno a chegar aonde você quer que ele chegue. Tirar média, moda e
mediana é fácil. Agora, como eu vou conduzir meu aluno para que ele saiba, num momento prático,
quando usar a média, a moda ou a mediana?

Fonte: Dados da pesquisa.

Nesse episódio, percebemos que o Professor G reconhecia sua dificuldade na aplicação das MTC, o que também fora observado em seus registros no Questionário Inicial. Esse profissional, juntamente com os professores C, D e E, concordou com o aspecto de que o enunciado pode ser falso devido à média não ser um número inteiro. Isso indicou que esses docentes não reconheciam a propriedade da média, apontada por Strauss e Bichler (1988), quanto à natureza numérica dessa medida. A partir disso e considerando que esses professores já haviam lecionado tal conteúdo ${ }^{3}$, é possível deduzir que eles tenham trabalhado exemplos em sala de aula cujos resultados tivessem a mesma natureza numérica dos dados analisados, ou, então, tenham focado nos procedimentos para a obtenção dessa medida, sem propiciarem análises e discussões do valor calculado

Diante disso e a fim de aprofundar os significados e conceitos das MTC, o Pesquisador 2 acrescentou que, em certos momentos, saber somente os valores da média, da mediana e da moda não possibilita enxergar o real comportamento dos dados do conjunto analisado. Para exemplificar, ele apresentou duas sequências de valores, que foram registrados na lousa (Figura 8). 
Figura 8 - Valores do exemplo proposto pelo Pesquisador 2

\begin{tabular}{|c|c|}
\hline Sala A & Sala B \\
\hline 2,0 & 5,0 \\
\hline 3,0 & 5,0 \\
\hline 3,0 & 6,0 \\
\hline 10,0 & 6,0 \\
\hline 10,0 & 6,0 \\
\hline
\end{tabular}

Fonte: Dados da pesquisa.

A partir dos dados elencados na lousa, o Pesquisador 2 propôs o seguinte contexto:

Considere que aqueles valores se referem às notas que os alunos de duas salas obtiveram em uma mesma prova. A média da nota dos alunos em cada uma das salas é igual a 5,6. As duas salas não têm o mesmo comportamento. Ao passo que na turma A temos dois alunos que foram muito bem, os outros não foram. Já a turma $B$ foi mais homogênea. Nesse caso, você precisa calcular a medida de dispersão. Ou seja, qual o grau de dispersão dos valores em torno da média. $\mathrm{Na}$ turma A, o grau de dispersão é grande, mas, em B, os valores estão mais concentrados em torno da média. Então a gente também precisa trazer para o aluno que só a média, a mediana e a moda não dão o quadro exato da situação. Você precisa saber o grau de dispersão, ou seja, o quanto esses dados estão afastados ou concentrados em torno da média. [...] Saber a medida de tendência central é importante, mas também tem que entender, o quão dispersos estão aqueles valores. Em uma questão como esta, você mostra para o aluno que em certos momentos é necessário utilizar outras medidas para que dê o retrato real da situação (Pesquisador 2).

A proposta apresentada pelo Pesquisador 2 possibilitou que ele demonstrasse ao grupo de professores a importância de considerar o contexto em que os dados estão inseridos, criticando as medidas obtidas e uma situação em que a análise do grau de dispersão dos dados pode ser imprescindível para garantir uma visão real do contexto estudado.

Visando sistematizar os conhecimentos abordados durante a realização dessa atividade, o Pesquisador 1 enfatizou que, logo de imediato, o grupo havia optado pela moda para solucionar o problema proposto. Com base nisso, ele fez o seguinte questionamento aos participantes: "E em relação às outras medidas, por que elas não foram escolhidas pelo grupo?".

Diante disso, o Professor $\mathrm{H}$ acrescentou que a média poderia apresentar um valor que não teria significado algum para o contexto proposto: "Ia dar alguns calçados com meio pé. Por exemplo, a média igual 42,5 não teria sentido".

Com o intuito de instigar os professores, o Pesquisador 1 apresentou outro contexto: "E se os números dos calçados fossem 36 e somente dois fossem 42 e 43, o que aconteceria?".

Então o Professor $\mathrm{H}$ comentou que, se fosse calcular a média, poderia obter um número, mesmo que inteiro, como 38, e não atender a ninguém no caso da fabricação dos calçados. O Professor I acrescentou que optar por alguma das MTC deve estar relacionado ao contexto analisado: "Por isso que depende de cada situação".

Além disso, o Professor $\mathrm{H}$ apresentou ao grupo como abordava tal conteúdo com seus alunos:
Essa ideia do calçado é a primeira que passo para os alunos, quando vou explicar média, moda e mediana. Eu pego o número dos calçados dos alunos ali mesmo na sala e mostro para eles. Quando a gente joga uns dados no quadro, eles olham aquilo e pensam: onde eu vou utilizar isso? Então eu faço isso, eu pego o número dos calçados, a idade dos alunos e faço essas situações. Nesse exemplo do calçado, o lojista venderia que número para essa sala de aula, que tênis ele traria aqui para vender? (Professor $\mathrm{H}$ )

Para Zeichner (2008), a reflexão do professor sobre sua própria experiência, assim como percebemos na fala do Professor $\mathrm{H}$, é o ponto de partida para que o docente realize o processo de compreensão e de melhoria de seu próprio ensino. Assim como o autor, consideramos que, à medida que a reflexão sobre a prática ocorre, também observamos análises críticas que podem favorecer a reestruturação e a incorporação de novos conhecimentos que vão justificar futuras ações docentes.

\section{Conclusão}

Neste estudo tínhamos o propósito de compreender quais são os conhecimentos explicitados e as reflexões geradas durante uma sessão de formação continuada, que se propôs a discutir e refletir sobre os significados das Medidas de Tendência Central a partir da análise de situações contextualizadas.

No encontro formativo aqui analisado, houve o desenvolvimento e a análise de situações que nos permitiram aprofundar nossa compreensão acerca dos conhecimentos de características e propriedades das MTC do grupo de professores. Procuramos reforçar, por meio das discussões e reflexões, a perspectiva da prática docente de ensino e as possíveis dificuldades que os alunos poderiam vivenciar durante o aprendizado da temática escolhida.

$\mathrm{O}$ desenvolvimento dessa atividade possibilitounos levar à reflexão entre os professores alguns aspectos importantes das MTC, sobretudo da moda. Em paralelo, foram trabalhados conceitos que serviram de base para aprimorar os conhecimentos profissionais docentes, sobretudo o Conhecimento do Conteúdo e do Ensino descrito por Ball et al. (2008), visto que foram discutidas maneiras que os professores poderiam utilizar para lecionar o conteúdo aos seus alunos. Além disso, há indícios de ampliação do nível de Letramento Estatístico dos participantes desta investigação.

Assim, foram apontados, por exemplo, alguns aspectos limitadores das MTC: a amostra analisada pode não ser representativa para a realidade; em um conjunto de dados, cujas variáveis são de natureza qualitativa, a média e a mediana são valores de pouco significado para o contexto analisado, enquanto a moda é a mais adequada e dois ou mais conjuntos, mesmo que as MTC de ambos sejam de valores iguais entre si, podem ter comportamentos totalmente diferentes, sendo necessária a análise da dispersão dos dados para a adequada tomada de decisão.

Em relação às reflexões apresentadas, a do Professor 
$\mathrm{G}$ nos chamou bastante a atenção por estar relacionada à prática de ensino. Ele, durante toda essa sessão de formação, mostrou-se bastante interessado em participar das discussões. Especificamente nesta atividade, o docente retratou que, mesmo sabido o cálculo da média, da mediana e da moda, ele reconhecia como grande dificuldade para o professor saber mostrar ao aluno o momento de aplicação de cada uma dessas medidas.

A fim de favorecer a ampliação de tal conhecimento, decidimos retomar aspectos dessa natureza em atividades posteriores - Medidas de dispersão - para que os professores tivessem que julgar as características das MTC e tomá-las como base em suas decisões.

Temos convicção de que foipossível alcançartais resultados, devido à maneira como o curso de formação continuada foi desenvolvido. Nele, os professores eram motivados a discutir e refletir em grupo (Zeichner, 2008) e verificamos que, fazendo isso de modo natural, eles se sentiam à vontade para expor suas concepções e questionamentos. Mesmo quando alguns participantes se sentiam desconfortáveis para apresentar suas limitações, outros professores, que tinham a mesma percepção, apresentavam-na em discussão. Além disso, não determinamos teorias iniciais a serem provadas, mas, sim, investigamos as perspectivas dos professores ao analisarem o conteúdo das MTC para seu ensino. Como implicação desta pesquisa sugerimos que cursos dessa natureza sejam desenvolvidos tanto na formação inicial como continuada.

\section{Referências}

Alves, T. A. S. (2016). Conhecimentos de professores de matemática da educação básica sobre o ensino de medidas de tendência central. 112f. Dissertação (Mestrado em Educação Matemática). Programa de Pós-graduação em Educação Matemática, Universidade Anhanguera de São Paulo/ UNIAN, SP, 2016.

Arteaga, P., Batanero, C., Cañadas, G. \& Gea, M. (2012). Evaluación del Conocimiento especializado de la estadística en futuros profesores mediante el análisis de un proyecto estadístico. Educação Matemática y Pesquisa. 14(2), 279297.

Ball, D. L., Thames, M. H. \& Phelps, G. (2008) Content knowledge for teaching: What makes it special?. Journal of Teacher Education, 59(5), 389-407.
Batanero, C. Y. \& Godino, J. (2005). Perspectivas de la educación estadística como área de investigación. In: R. Luengo (Ed.) Líneas de investigación en Didáctica de las Matemáticas (pp. 203-226). Badajoz: Universidad de Extremadura.

Bogdan, R. C. \& Biklen, S. K. (1994). Investigação qualitativa em educação: uma introdução à teoria e aos métodos. Porto: Porto.

Brasil. (2018). Ministério da Educação. Base Nacional Comum Curricular - Educação é a Base. Brasília: MEC.

Gal, I. (2004) Statistical Literacy: Meanings, Components, Responsibilities. In: BEM-ZIV, D., GARFIELD, J. The Challenge of Developing Statistical Literacy. (pp. 47-78). Dordrecht: Kluwer Academic Publishers.

Kataoka, V. Y., Souza, A. A., Oliveira, A. C. S., Fernandes, F. M. O., Paranaíba, P. F., \& Oliveira, M. S. (2008). Probability teaching in brazilian basic education: evaluation and intervention. In Anais, 11th International Congress on Mathematical Education. Monterrey, Mexico.

Macedo, R. C. (2016). Conhecimentos de professores de matemática sobre o processo de ensino e de aprendizagem de noções estatísticas - curva normal. Dissertação de Mestrado, Universidade Anhanguera de São Paulo, Programa de Pósgraduação em Educação Matemática, São Paulo.

Santana, F. C. M \& Barbosa, J. C.. Um estado do conhecimento sobre trabalho colaborativo com professores de matemática: uma análise de artigos publicados no Brasil. Boletim GEPEM, n. 67, p. 69-84, jun./dez. 2015.

Sera, E. K. (2016) Conhecimentos de Professores para o Ensino da Leitura e Construção de Gráficos Estatísticos na Educação Básica. 2016. 215p. Dissertação (Mestrado em Educação Matemática). Universidade Anhanguera de São Paulo, São Paulo.

Shulman, L. S. (1986). Those who understand: Knowledge growth in teaching. Educational researcher, 15(2), 4-14.

Shulman, L. S. (1996). Just in case: Reflections on learning from experience. In Colbert, J. A., P. Desberg \& TrimbleK. (Ed.). The case for education: Contemporaly approaches for using case methods. (pp. 197-217). Boston: A 1 lyn \& Bacon.

Strauss, S. \& Bichler, E. (1988). The development of children's concepts of the arithmetic average. Journal for Research in Mathematics Education, 19 (1), 64-80.

Zeichner, K. M. (1993). A formação reflexiva de professores: idéias e práticas. Lisboa: Educa.

Zeichner, K. M. (2008) Uma análise crítica sobre a "reflexão" como conceito estruturante na formação docente. Educação \& Sociedade, 29 (103), 535-554. 